\title{
Managing Migration through Conflicting Policies: an Option-theory Perspective
}

\author{
MICHELE MORETTO \\ SERGIO VERGALLI
}

CESIFO WORKING PAPER NO. 2731

CATEGORY 4: LABOUR MARKETS

JULY 2009

Presented At CESifo Venice Summer Institute, July 2009
An electronic version of the paper may be downloaded
- from the SSRN website: www.SSRN.com
- from the RePEc website: www.RePEc.org
- from the CESifo website: www.CESifo-group.org/wp




\title{
Managing Migration through Conflicting Policies: an Option-theory Perspective
}

\begin{abstract}
Recent European legislation on immigration has revealed a particular paradox on migration policies. On the one hand, the trend of recent legislation points to the increasing closure of frontiers (OECD 1999, 2001,2004), trying to limit the immigrants' stock. On the other hand, there is an increase in regularization, i.e., European policies are becoming less tight. Our aim here is to develop a theoretical model that tries to explain if it is better for the government to tighten or relax limits for immigrants in order to control migration inflows better. To this end, we use a real option approach to migration choice that assumes that the decision to migrate can be described as an irreversible investment decision. In our model the government has in mind a specific upper bound on immigrants, and the policies adopted (admission requirements or regularizations) are signals for each potential migrant that reveal information about this limit. Our results show that promoting uncertainty over this migration upper bound may improve the government's control on migration inflows (quotas). This could explain that the paradox of counterbalancing policies is not an odd evidence. In particular, we show that if the government controls the information related to the immigration stock it could delay the mass entry of immigrants, maintaining the required stock in the long run and controlling the flows in the short-run.
\end{abstract}

JEL Code: F22, J15, J61, O15, R23.

Keywords: immigration, real option.

\author{
Michele Moretto \\ University of Padua \\ Department of Economics \\ via Ugo Bassi $n .1$ \\ Padua, 35131 \\ Italy \\ michele.moretto@unipd.it
}

\author{
Sergio Vergalli \\ University of Brescia \\ Department of Economics \\ via S.Faustino 74/b \\ Brescia \\ Italy \\ vergalli@eco.unibs.it
}

July 20, 2009 


\section{Introduction}

Although barriers to international trade and capital mobility have been largely removed, labour markets are still the most tightly regulated areas of economic activity (Faini et al., 1999). In this regard, Boeri and Brücker (2005), studying European migration, showed that rules for legal immigration into the EU from third countries are getting tighter and tighter: "since 1990 there have been 92 reforms of national migration policies into the EU-15, that is, more than five reforms per year. Most of these reforms are marginal in that they adjust specific provisions rather than revising the overall regulatory framework. Furthermore, seven reforms out of ten tighten regulations, for example, by increasing procedural obstacles faced by those applying for visas, reducing the duration of work permits or making family reunification more difficult", or by introducing an immigration quota system ${ }^{1}$. In particular, this latter immigration policy has been adopted by certain European countries (Austria, France, Greece, Italy, Portugal, Spain, UK) to control migration inflows better, and it was suggested at the meeting of the EU Justice and Home Affairs ministers in Stratford-upon-Avon in late October $2006{ }^{2}$. Nevertheless, despite this evidence, another aspect related to migration policy has revealed a peculiar paradox of migration policies. Since 1990, there have been 26 (39 since 1973) one-shot regularization programs in $10 \mathrm{EU}$ countries (Jachimowicz et al., 2004; Sunderhaus, 2007) ${ }^{3}$. Therefore, on the one hand, as a result of increased labour market competition and concerns about terrorism, the trend of recent legislation on immigration points to the increased closure of frontiers (OECD 1999, 2001). On the other hand, there are more regolarization programs which, as anticipated by the immigrants, reduce the control over the total quantity of immigrants admitted and make the European policies less tight.

What, therefore, is the effect of this ambiguity concerning European migration policies? Is it better to tighten or to relax limits on the migration stocks? As many countries have adopted simultaneously two kinds of conflicting immigration policies, it seems, at first glance, that the legislator has no clear idea about the matter. Moreover, this uncertainty reduces information about the migration stocks accepted in each country by the authorities: this entails that potential immigrants do not exactly know whether or not the ceiling is binding. Our aim in this paper is to answer these questions, by investigating the conflicting immigration policies in European immigration legislation in an unified framework.

By using a recent approach to migration choice, which assumes that the decision to migrate can be described as an investment decision (Sjaastad, 1962), we approach the above question by extending recent results obtained by Bartolini ${ }^{4}$ (1993; 1995). Bartolini shows that a competitive market reacts to limit ${ }^{5}$ aggregate investment by generating recurrent runs as the total investment approaches its ceiling. That is, the existence of limit on aggregate investment may induce endogenous and recurrent asset runs so that the stock limits are immediately filled. Specifically, the aggregate investment evolves smoothly over time, driven by market conditions, until it reaches an upper threshold where it shows a jump that fills the stock.

We show that, introducing uncertainty concerning the stock of immigrants allowed to enter in a competitive migration market, the entry run tends to vanish. Because each agent is not able to perfectly foresee the true upper limit, he acts as if the limit did not exist. The entry process tends to be smooth and has no jumps. The ambiguity concerning the true limit reduces the entry runs by potential immigrants, allowing the government to obtain, in the long run, the required immigration stock and to control flow in the short-run (i.e., the migra- 
tion quota accepted each year). In this context, the presence of regularization programs that make agents unable to perfectly foresee the limit is no longer a paradox, but it may be useful for the planner to control immigration inflow.

This paper is related to past research that applies the real option approach to migration phenomena. In this regard, Burda (1995), showed that individuals prefer to wait before migrating, even if the present value of the wage differential is positive, because of the uncertainty and the sunk costs associated with migration. Subsequently Khwaja (2002) and Anam et al., (2007) developed Burda's approach by describing the role of uncertainty in the migration decision. Another work that uses real option on migration is Feist (1998), in which the author analyses the option value for low-skilled workers of escaping to the unofficial sector if welfare benefits come too close to the net wage in the official sector. Three recent papers (Moretto and Vergalli, 2008; Vergalli, 2007; Vergalli, 2008) have applied the real option framework to the analysis of migration dynamics, focussing on the role of communities and network in explaining mass migration.

In the first part of this paper, we describe what happens in migration dynamics if the authority gives total information about the target number of immigrants it has in mind. This assumption means that the government adopts a policy in only one direction: in particular, it imposes a determined and known limit over the stock on the immigration entries and this ceiling is known to all the potential immigrants. In the second part, we show that the introduction of noise over the limit delays mass entry (i.e., flows). This uncertainty can be created either by announcing policies followed by different action by the government or by introducing different policies relaxing or tightening the conditions to immigrate. In both cases this uncertainty may also depend on governments with unstable majorities, that probably is expressed in counterbalancing migration policies ${ }^{6}$. This fact may also explain why recent legislation on immigration has moved in the two counterbalancing directions explained above. The result is that in this case, the migration inflow becomes smooth regardless of the particular policy adopted.

This paper is organised as follows. Section 2 summarises the evolution of national immigration policies. Section 3 presents the model and the basic assumptions. Section 4 develops the theoretical framework with a known upper limit on immigrants. Section 5 develops the theoretical framework with unknown limit over the stock and gets out the main results. Section 6 summarises the conclusions. Finally, the Appendix contains the proofs omitted in the text.

\section{Evolution in National Immigration Policies}

Immigration policies can be tightened by using different criteria. In this regard, Boeri and Brücker (2005) developed an aggregate policy index that describes "the trend in migration policies". The index is shown in Figure 1 and is obtained by taking the average of the following seven indicators: 1) admission requirements; 2) number of administrations involved; 3) length of first stay; 4) quotas; 5) residence requirement; 6) years to obtain a permanent permit; 7) asylum policy ${ }^{7}$. According to Boeri and Brücker's analysis national immigration policies are becoming tighter ${ }^{8}$. 


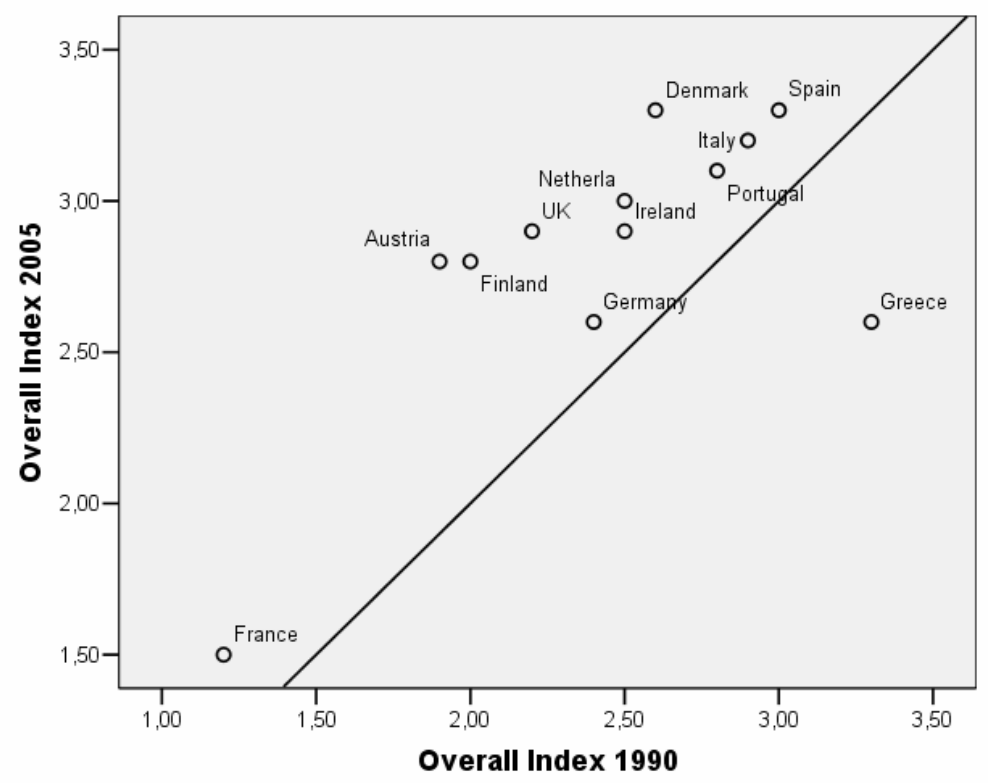

Figure 1: Boeri and Brücker immigration policy index. Comparison between 1990 and 2005

In order to study policies of this kind in depth, in table 1 we show the European countries that have recently introduced immigration quota systems, being Austria, Czech Republic, France, Greece, Italy, Portugal, Slovenia, Spain, Switzerland and the United Kingdom ${ }^{9}$. As table 1 shows, many European countries plan to spread quotas over several years (i.e. three/two-period quota for France, Spain and Czech Republic). Since a quota is defined as "a share of the total immigrants allowed to enter the host country", this means that the governments use year quotas to distribute the total stock of immigrants they have programmed over some years. 


\begin{tabular}{|c|c|c|}
\hline Country & Quota & Source \\
\hline Austria & $\begin{array}{l}\text { - In 1990, a quota for the employment of foreigners was introduced, defined as } \\
\text { a maximum share of foreign workers in the total workforce. } \\
\text { The Residence Act } 1993 \text { has the objective to control immigration. It defines } \\
\text { the quantitative and qualitative criteria for the potential residence of different } \\
\text { groups of foreigners: definition of quotas for certain sub-groups of } \\
\text { immigrants (family members). } \\
\text { The Aliens Law } 1997 \text { (Fremdengesetz) came into effect in 1998. It regulates } \\
\text { the conditions for entry and residence in the country. The key concept of the } \\
\text { reform is: "Integration Before New Immigration". Reduction of immigration } \\
\text { quotas. } \\
\text { The Aliens Law } 2002 \text { changes the conditions of entry and residence in the } \\
\text { country, it provides for a stricter system of immigration control and it tightens } \\
\text { the quota system. Key professional are not subject to quotas, don't have to } \\
\text { fulfilll the integration agreement and can obtain a residence permit with the } \\
\text { authorization to work. }\end{array}$ & $\begin{array}{l}\text { Federal Ministry for Internal Affairs, } \\
\text { Migration Information Source, } \\
\text { European Migration Network, } \\
\text { Fondazione Rodolfo De Benedetti }\end{array}$ \\
\hline $\begin{array}{l}\text { Czech } \\
\text { Republic }\end{array}$ & $\begin{array}{l}\text { - The Czech government launched in } 2002 \text { a pilot programme for the active } \\
\text { selection of the qualified foreign workers. The puotas were established for the } \\
\text { first two years }-600 \text { and } 1200 \text { persons for } 2003 \text { and } 2004 \text { respectively }\end{array}$ & OECD \\
\hline France & $\begin{array}{l}\text { - In } 2006 \text {, the government has been required to submit to parliament an annual } \\
\text { report specifying the number and kind of residency permits to be authorized } \\
\text { over a three-year period. The draft bill avoids using the word "quotas," but } \\
\text { critics say the provision amounts to a quota-system". } \\
\text { - In } 2007 \text { the government decided to adopt decrees on immigration quotas "by } \\
\text { profession, category and, naturally, by regions of the world" }\end{array}$ & Work Permits \\
\hline Greece & $\begin{array}{l}\text { - The Law } 1975 / 1991 \text { defines for the first time the legal situation of migrants } \\
\text { and refugees. It's an attempt to modernize the relevant legislation on issues of } \\
\text { entrance, exit, stay, settlement, employment and expulsion of aliens. } \\
\text { The Law } 2910 / 2001 \text { reorganizes the procedure concerning work permits: the } \\
\text { Manpower Employment Organization at the end of every year prepares a report } \\
\text { recording the current needs in Greek labour market, a resolution based on this } \\
\text { report shall set forth the maximum number of work permits to be granted every } \\
\text { year. }\end{array}$ & European Migration Network \\
\hline Italy & $\begin{array}{l}\text { - The Law } 39 / 1990 \text { (Martelli Law) regulates the entry and the residence of non- } \\
\text { EU citizens: migration begins to be considered as a stable phenomenon. The } \\
\text { law defines the conditions to grant entry permits for working reasons: the } \\
\text { Government has to draw up a yearly plan instead of referring to pre-defined } \\
\text { criteria. This is the first law that bruits the idea of quotas. } \\
\text { - With ministry of Employment's decree } 15 \text { February 2006, were defined the } \\
\text { non-EU immigrant quotas. }\end{array}$ & $\begin{array}{l}\text { European Migration Network, } \\
\text { Fondazione Rodolfo De Benedetti } \\
\text { Sopemi-OECD }\end{array}$ \\
\hline Portugal & $\begin{array}{l}\text { - The Decree-Law 34/2003 introduces a system of quotas to regulate the entry of } \\
\text { migrants. Every year, depending on economic and labour market condition, the } \\
\text { maximum number of foreigners allowed to enter the country is fixed by the } \\
\text { Government. }\end{array}$ & Fondazione Rodolfo De Benedetti \\
\hline Slovenia & $\begin{array}{l}\text { - The Employment and Work of Aliens Act is the main act regulating the } \\
\text { economic migration in Slovenia. It sets the policy priorities as well as the } \\
\text { maximum quotas of admitted workers }\end{array}$ & OECD \\
\hline Spain & $\begin{array}{l}\text { - The quota system is the basic mechanism used in managing the labour } \\
\text { immigration in Spain. } \\
\text { It was used in the years 1993-1995, 1997-1999 and since 2002. The aim of the } \\
\text { quotas was to direct the immigrants to the labour market sectors which suffered } \\
\text { from shortages. }\end{array}$ & $\begin{array}{l}\text { Migration Information Surce, } \\
\text { Fondazione Rodolfo De Benedetti } \\
\text { Sopemi - OECD }\end{array}$ \\
\hline Switzerland & $\begin{array}{l}\text { - The Swiss government relaxed its immigration laws on } 01 \text { June } 2007 \text {. Quotas } \\
\text { will remain in place for these countries untit at least } 2011 \text {. The previous system } \\
\text { allowed } 15,000 \text { permanent residence permits to be granted annually for people } \\
\text { who had a job contract for more than one year. This quota was quickly } \\
\text { exhausted each year. Short term permits, allocated at } 115,000 \text { per year, were } \\
\text { less popular, with only } 55 \%-90 \% \text { being used. }\end{array}$ & Workpermits \\
\hline $\begin{array}{l}\text { United } \\
\text { Kingdom }\end{array}$ & $\begin{array}{l}\text { For unskilled workers: } \\
\text { Working Holiday Makers - around } 46,000 \text { young people from } \\
\text { Commonwealth countries (17-27 years old) are allowed to come to Britain } \\
\text { and take up non-professional job for up to } 2 \text { years; } \\
\text { seasonal agricultural workers - for students, mainly form Central and Eastern } \\
\text { Europe, who arrive within a set quota (Food Manufacturing Fish and Meat } \\
\text { sector in the context of Sector Based Scheme Pemits); } \\
\text { - Au pairs - around } 15,000 \text { per annum; } \\
\text { Domestic workers - around 15,000 per annum (Spencer 2002). }\end{array}$ & Work Permits, World Bank, OECD \\
\hline
\end{tabular}

Table 1: immigration quota system adopted in some countries

To be complete in the analysis of migration policies, we must also add another instrument that governments can use to control migration: regularization programs which, by definition, relax the effect of limits on the stock and at the same time modify immigrant flows and stocks. Hence, inspections at European legislation (see Figure 1 and table 1), show that several countries impose both admission requirements and quotas to reduce entry. Nevertheless, they also adopt frequent regularization programs. Table 2 shows the regularization programs adopted in Europe since $1973^{10}$. Since 1990, there have been 26 (39 since 1973) one-shot regularization programs in $10 \mathrm{EU}$ countries. 


\begin{tabular}{|lcl|}
\hline Country & Regularizations & \multicolumn{1}{c|}{ Years } \\
\hline Belgium & 3 & $1974-1975,1995-1999,2000$ \\
France & 5 & $1973,1979,1981-1982,1991,1997-1998$ \\
Germany & 2 & 1996,1999 \\
Greece & 2 & $1997-1998,2001$ \\
Italy & 6 & $1982,1987-1988,1990,1996,1998-1999,2002$ \\
Luxembourg & 1 & 2001 \\
Netherlands & 5 & $1964,1975,1978-1979,1991-1994,1996$ \\
Portugal & 3 & $1992-1993,1996,2001$ \\
Spain & 7 & $1985-1986,1991,1994,1996,2000,2001,2005$ \\
United Kingdom & 5 & $1974-1978,1977,1987,1998-1999,2004$ \\
\hline Total & 39 & \\
\hline
\end{tabular}

Table 2: Regularization Programs in 10 EU countries.

There is no doubt that all these seven policies mirror European immigration policy. Nevertheless, for some of these policies we should distinguish between short and long term also among their effects on migration flows and/or migration stocks. For example, consider what happens when a government has in mind a given target for the total number of immigrants that should enter and it announces immigration policies that tighten the admission requirements (this can be done by exacerbating some of the indicators shown above). This policy announcement reveals whether or not the immigrant stock is close to its upper limit. Therefore, if there is a tightening of migration policies, the potential immigrants believe that the "open door" of migration is closing and they may decide to run to enter. We thus have two counterbalencing effects of a migration limit: on the one hand the limits may be able to control migration stocks in the long run (if the authority does not change the target stock by relaxing the ceilings afterwards), on the other hand it may trigger run-entry mechanisms that may thwart any control of inflow and its speed. That is, limits on the stock are useful for controlling, at least in the long run, the total number of immigrants (stock) but not the entry speed (flow). In particular in the EU there has been a tightening of immigration policies supported by the increase of immigration quotas. Moreover, this effect is stronger when the limit on the stock is perceived by immigrants as their last chance to enter: they all hurry to enter the host country.

\section{The Model}

\subsection{The basic assumptions}

For simplicity, the model uses the familiar terminology of an agents' entry decisions under uncertainty ${ }^{11}$. Consider the immigration decision of individuals in a host country subject to an uncertain wage gap. Let us summarize the main assumptions:

1. At any time $t$, a potential immigrant may decide to migrate ("entry"). Individuals are risk-neutral and discount future income at the constant discount rate $\rho$.

2. Each individual can migrate by committing irrevocably to a flow cost $w$ or undertaking a single irreversible investment which requires an initial sunk cost $K=w / \rho$. 
3. $n_{t}$ is the number of individuals in the host country at time $t$, each yields a net ${ }^{12}$ flow of income ${ }^{13}$ :

$$
\pi\left(\theta_{t}, n_{t}\right) \equiv u\left(n_{t}\right) \theta_{t}
$$

where $\theta$ is a multiplicative labour market-specific shock. We can consider, in a simpler setting, $u\left(n_{t}\right)$ as the inverse demand function (Dixit and Pindyck, 1994, ch. 9; Bartolini, 1993; Nielsen, 2002) or as a reduced form of a more general benefit function (Dixit and Pindyck, 1994, ch. 11; Dixit, 1995; Grenadier, 2002; Moretto and Vergalli 2008). Time is continuous, $t \in[0, \infty)$, and suppressed if not necessary.

4. The function $u(n)$ is continuously differentiable in $n$ with the usual properties.

$$
\begin{gathered}
u(n)>0, u^{\prime}(n)<0 \\
\lim _{n \rightarrow 0} u(n)=+\infty \quad \text { and } \quad \lim _{n \rightarrow \bar{N}} u(n)=\underline{u}>0
\end{gathered}
$$

where $\bar{N} \leq \infty$ can be interpreted as the upper saturation level of the ethnic community in the host country ${ }^{14}$. Hence, a positive reserve "utility" $\underline{u}$ means that for each immigrant the benefits from migration (even in the worst case) are higher than the costs (in the wider sense) of migrating. ${ }^{15}$

5. All individuals are identical and their size $d n_{t}$ is infinitesimally small with respect to the labour market in the host country.

6. The labour market-specific shock follows a geometric diffusion process ${ }^{16}$ :

$$
d \theta_{t}=\alpha \theta_{t} d t+\sigma \theta_{t} d W_{t} \quad \text { with } \theta_{0}=\theta \text { and } \alpha, \sigma>0
$$

where $\alpha<\rho$ and $d W_{t}$ is the increment to a Wiener process, satisfying $E\left(d W_{t}\right)=0$ and $\operatorname{Var}\left(d W_{t}\right)=d t^{17}$.

In the next section, we assume that the limit on the stock is known to the immigrants. The existence of a ceiling on the aggregate level of migration induces an externality among the benefit functions of different immigrants, which causes a possible divergence between the socially-optimal and profit-maximizing policies. Then, in section 4 we relax this assumption by assuming that the immigrants may not know the true stock.

\subsection{Solution when the upper limit on the total immigrants is known}

For the first result we have added the following assumption:

7. There exists an exogenously determined limit on the stock $N<\bar{N}$ on $n$, which is announced by the government and is known to all the potential immigrants.

To determine the migrant's optimal entry policy, the first thing to do is to find his/her value, given each individual's optimal future entry policy. Let us consider the value of an immigrant $V(\theta, n, N)$, who is active in the market, as the expected discounted stream of income:

$$
V(\theta, n, N)=\max _{\tau} E_{0}\left[\int_{0}^{\infty} e^{-\rho t} \pi\left(\theta_{t}, n_{t}\right) d t-J_{[t=\tau]} K \mid n_{0}=n, \theta_{0}=\theta\right]
$$


where $J_{[t=\tau]}$ is the indicator function and the expectation is taken considering that the number of active immigrants may change over time because of new entry. The solution to (3) can be obtained by starting within a time interval in which no new entry occurs. Over this interval the number of immigrants $n$ is fixed and $V(\theta, n, N)$ must satisfy the no-arbitrage requirement ${ }^{18}$ where time is suppressed if not necessary:

$$
\pi(\theta, n)+E[d V(\theta, n, N) / d t]=\rho V(\theta, n, N)
$$

Assuming $V(\theta, n, N)$ to be a twice-differentiable function with respect to $\theta$ and using Itô's Lemma to expand $d V(\theta, n, N)$, the solution of (3) is given by the following differential equation (Dixit and Pindyck, 1994, p. 179-180): ${ }^{19}$

$$
\frac{1}{2} \sigma^{2} V_{\theta \theta}(\theta, n, N)+\alpha V_{\theta}(\theta, n, N)-\rho V(\theta, n, N)+\pi(\theta, n)=0
$$

The general solution of (5):

$$
V(\theta, n, N)=B(n, N) \theta^{\beta}+\frac{\theta u(n)}{\rho-\alpha}
$$

where the last term $\left(\frac{\theta u(n)}{\rho-\alpha}\right)$ represents the value of migration in the absence of new entry ${ }^{20}$. Then $B(n, N) \theta^{\beta}$ is the correction of the migration's value due to the new entry and $B(n, N)$ must therefore be negative. Obviously, a last boundary condition applies to the value of the $N^{t h}$ entry. The value of the $N^{t h}$ entry should converge to the value of a migration calculated by keeping the number of immigrants fixed at $N$, i.e. $V(\theta, n, N)=\frac{\theta u(N)}{\rho-\alpha}$. This implies that:

$$
B(N, N)=0 .
$$

If the benefit value function (6) is known, the optimal migration policy implies that the return from migration must be at least equal to cost $K$ at the entry point. In other words, we need to find the trigger value $\theta^{*}(n)$ (i.e. the value of the labour demand shock) at which the $n$th migrant is indifferent between immediate entry or waiting another instant. This trigger should be calculated bearing in mind that $N$ is the upper limit and that above this limit no new entry is allowed. ${ }^{21}$ This is defined in the following proposition:

Proposition 1 The benefit-maximizing entry policy in a market with a limit $N$ is given by:

$$
\begin{aligned}
\theta^{*}(n) & =\frac{\beta}{\beta-1}(\rho-\alpha) \frac{K}{u(n)} & \text { for } n=\left(0, n^{*}\right] \\
\theta^{*}\left(n^{*}\right) & =\theta^{*}(N) & \text { for } n=\left[n^{*}, N\right]
\end{aligned}
$$

where $\theta^{*}(N)=(\rho-\alpha) \frac{K}{u(N)}$.

Proof. See Bartolini (1993) and the Appendix.

By Proposition 1, the entry policy is efficient until a number $n^{*}<N$ of individuals has entered the market. At that point a migration run takes place and the residual stock is instantly filled. As proved by Bartolini (1993), $n^{*}$ is determined by the fact that it splits the interval $(0, N]$ into two subintervals. In the first interval, the individuals enter by following the usual matching value and smooth pasting conditions, i.e. $V\left(\theta^{*}(n), n, N\right)=K$ and $V_{\theta}\left(\theta^{*}(n), n, N\right)=0$, so that $\frac{d \theta^{*}(n)}{d n}>0$ (see the Appendix) ; in the second interval, the individuals 
migrate by a "run" until the whole stock is instantly filled, i.e. $\frac{d \theta^{*}(n)}{d n}=0$, while, from (8) and (9), $n^{*}$ is given by:

$$
\frac{u\left(n^{*}\right)}{u(N)}=\frac{\beta}{\beta-1}
$$

The insights from Proposition 1 are shown in Figure 2, below. In particular:

i) In the first quadrant on the left, on the abscissa, stands the entry value for different $\theta$ and $n$ levels. The migration value of the first $n^{*}$ immigrants follows the S-shaped curve typical of the model of investment hysteresis (Dixit and Pindyck, 1994, p. 220). These curves are tangential to the barrier (i.e., the entry cost) $K$ and describe the value of migration as long as it fluctuates under the $K$ level. The last $\left(N-n^{*}\right)$ curves cross the level $K$, and all of them must cross $K$ at the same level of fundamentals $\theta .^{22}$ Whenever $V(\theta, n, N)$ reaches $K$, the number of immigrants increases, shifting the current curve rightwards. When $n$ reaches $n^{*}$, a large change in $n$ shifts the current curve from $V\left(\theta, n^{*}, N\right)$ to $V(\theta, N, N)$.

ii) The second quadrant on the right shows the threshold levels for different numbers of immigrants. Below or to the right of the curve no migration occurs because at a given level $\theta(n)<\theta^{*}(n)$, the benefit for each potential immigrant is lower than the cost of migrating. This means that above the curve it is optimal to migrate. A wave of migrants will enter in a lump to move the benefit level immediately to the threshold curve. In the region below the curve the optimal policy is inaction. But the shock can cross the trigger for different numbers of individuals, $n$. To appreciate the explanation of Figure 1, let us consider a sequential entry starting at $n<n^{*}$. If the initial size of the community is $n<n^{*}$, we can expect migration to work in the following way. For any fixed $n$, if the benefits climb to a certain level $\pi^{*}=u(n) \theta^{*}(n)$, migration becomes feasible, the network size increases from $n$ to $n+d n$ and the benefits go downwards along the function $u(n) .{ }^{23}$ If the size of the community is $n^{*} \leq n \leq N$, when the shock hits the threshold $\theta^{*}(n)$, then the stock is instantaneously filled and a mass $(N-n)$ of individuals enter and the benefits climb to $\pi^{*}=u(N) \theta^{*}(N)$. Therefore, until $n^{*}$ the individuals migrate in a smooth manner, but between $n^{*}$ and $N$ they enter in a mass because for $\left(N-n^{*}\right)$, individuals the threshold level is the same. 


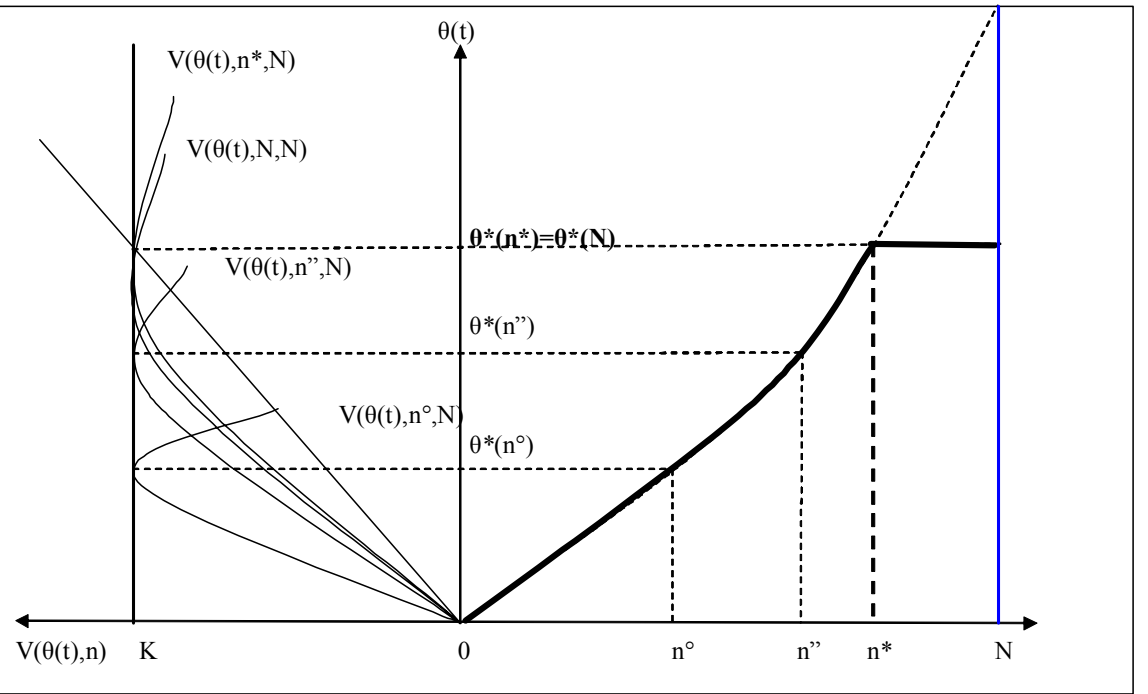

Figure 2: Optimal threshold levels with known stock N

Summarizing, with free entry, labour market competition generates a run that fills the stock when a fraction $n^{*} / N$ has been filled. Until then, the entry policy is identical to the case without a limit. Immigrants initially enter at the optimal pace, knowing that all the potential benefits will dissipate by the early entry of the last $\left(N-n^{*}\right)$ individuals.

\section{Solution when the upper limit on total immi- grants is unknown}

So far we have analysed the optimal policy with a fixed-known limit on the stock of the number of individuals admitted to the host country. But what happens if the limit is perceived to be uncertain by immigrants? To introduce uncertainty on the limit, we replace assumption (7) with the following assumption:

7 bis. Each individual does not know the exact limit on the stock imposed by the government ${ }^{24}$. However he/she knows that the limit is continuously distributed and drawn from a common distribution function $F(N)=\operatorname{Pr}(\mathcal{N}<N)$ which is strictly increasing in the interval $[0, \bar{N}]$, where $\bar{N}$ is the upper support of the distribution of $\mathcal{N}$, and it has a continuous differentiable density $f(N)^{25}$.

Further, we assume that each individual makes rational conjectures about the distribution of $\mathcal{N}$ over time. More specifically, as new individuals decide to migrate, the individual will update his/her conjecture about $\operatorname{Pr}(\mathcal{N}<N)$. As time goes by and $n$ increases, the potential immigrant learns that the probabilty of hitting the limit is higher. The individual then observes the realization of the state variable $n$ and updates his/her conjecture by using $G(N ; n)=\operatorname{Pr}(\mathcal{N}<N) \mid \mathcal{N}>n)=\frac{F(N)-F(n)}{1-F(n)}$ which is strictly increasing in the interval $[n, \infty)$, with density $g(N ; n)=\frac{f(N)}{1-F(n)}$.

Since the individuals now do not know the true limit, the value of their decision cannot be defined by (6). In particular, the last boundary condition (7) calculated by keeping the number of immigrants fixed at $N$ should be substituted by:

$$
\lim _{n \rightarrow \bar{N}} E(B(n))=0
$$


where the expectation operator is taken with respect to the random variable $\mathcal{N}$.

As before, also in this case, we should find the threshold level $\theta^{*}(n)$ that corresponds to the optimal entry process. Taking condition (11) into account, we can prove the following proposition:

Proposition 2 The benefit-maximizing entry policy in a market with an unknown stock is given by:

$$
\begin{aligned}
\theta^{*}(n) & =\frac{\beta}{\beta-1}(\rho-\alpha) \frac{K}{u(n)} \quad \text { for } \quad n=\left(0, n^{* *}\right] \\
\theta^{*}\left(n^{* *}\right) & =\frac{\beta}{\beta-1}(\rho-\alpha) \frac{K}{u\left(n^{* *}\right)} \quad \text { for all } n>n^{* *}
\end{aligned}
$$

where $n^{*}<n^{* *}$.

Proof. see the Appendix.

Proposition 2 states that the entry policy is efficient until a number $n^{* *}$ of immigrants has entered the market. At that point, a migration run starts until the true (unknown) stock is reached. That is, since the true limit is unknown, the migration run continues until the government stops entries because the predefined limit has been reached. In addition, it is evident from (12) and (13) it is evident that the optimal trigger $n^{* *}$ is obtained by considering all supports of the distribution $F(N)$, i.e., each individual acts as if the limit does not exist and the utility to remain out of the country is close to zero:

$$
\frac{u\left(n^{* *}\right)}{\underline{u}}=\frac{\beta}{\beta-1}
$$

nally, by direct inspection of (10) and (14), it is immediate obvious that $n^{* *}>n^{*}$ as long as $u(N)>\underline{u}$.

To interprete these results, consider Figure 3. In particular, in the quadrant on the left we have the value of the immigrants on the horizontal axis and the threshold level on the vertical axis. In the quadrant on the right, we have the threshold level on the vertical axis, and the number of immigrants in the host country on the horizontal axis. The red line represents the optimal trigger as a function of the number of immigrants. By comparing Figure 2 and Figure 3, we can see that while, without uncertainty, the optimal threshold level flattens at $n^{*}$, under uncertainty the competitive run starts at $n^{* *}>n^{*}$ and continues until the true (unknown) limit is reached. 


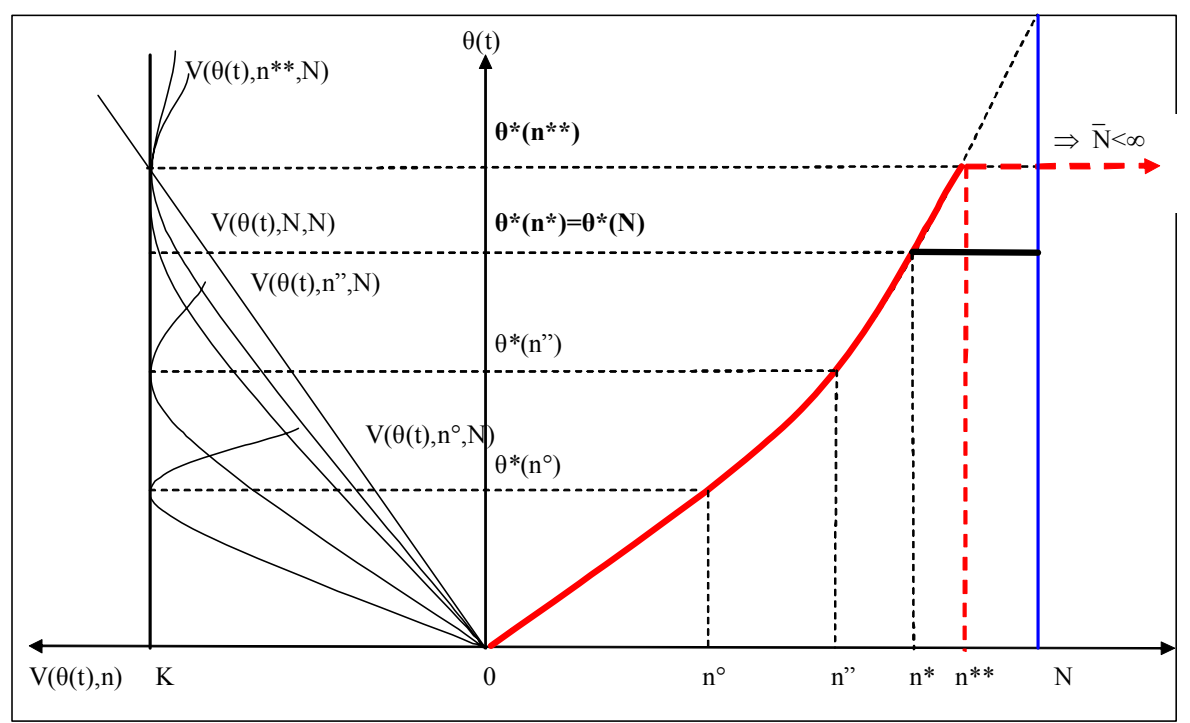

Figure 3: Optimal threshold levels with unknown stock

Therefore, if different political parties alternate in the government of a country, they probably express different and conflicting migration policies. This ambiguity, concerning the tightening (by exacerbating quotas or admission requirements) or the relaxing (by using regularization programs) of the limit on stocks, may increase especially in countries with unstable majorities. The result is that, in this case, the migration inflow becomes smooth independently of the particular policy adopted.

A policy remark about this result is in order. Comparing the two rules (10ne) and (14) yields:

$$
\frac{u\left(n^{* *}\right)}{u\left(n^{*}\right)}=\frac{\underline{u}}{u(N)}
$$

which means that the ratio between $n^{* *}$ and $n^{*}$, does not depend on the distribution of the stock $F(N)$ but only on the ratio between $\underline{u}$ and $u(N)$. If by adopting repeated regularization programs a country is able to generate noise over the true limit $N$, and to instill the idea in immigrants that the labour market's saturation level may increase, the entry jump is moved forward. That is, the entry run happens at a higher size $n^{* *}$, corresponding to a higher benefit level $u\left(n^{* *}\right) \theta^{*}\left(n^{* *}\right)$, which means that the stock is fulfilled later. In other words, if the government's goal is to delay migration waves and smooth entries, it can do so by controlling information on the immigration stock.

\section{The effect of labour market uncertainty}

Our model allows for deeper study of the effect of uncertainty concerning labour demand on entry policy as well as on the optimal triggers $n^{*}$ and $n^{* *}$. From (8) (or 12), (10) and (14) we can show that: ${ }^{26}$

$$
\frac{d \theta^{*}(n)}{d \sigma}>0
$$

and

$$
\frac{d n^{*}}{d \sigma}<0 \quad \text { and } \quad \frac{d n^{* *}}{d \sigma}<0
$$


As anticipated by the Real Option Theory, an increase in the labour demand volatility $(\sigma)$ increases the $\frac{\beta}{\beta-1}$ ratio which, in turn, raises the threshold of $\theta^{*}(n)$ for any given number of immigrants $n$. In this sense, greater uncertainty implies less willingness to migrate. However, as shown by (17), greater uncertainty magnifies the competitive effect, reducing the size that triggers the entry run. Therefore, depending on what kinds of effect prevail, we may get two entry patterns, as shown in Figure $4 .{ }^{27}$ If the uncertainty effect is soft, then the deriving competition effect, from a decrease in the crucial level $n^{* *},<n^{* *}$ is stronger than the entry delay caused by the raising of the threshold level (lower bold dotted line in figure). Entry is pushed forward because of the decrease of competition and, although we observe a reduction in immigration flow, the average time taken to reach the government's predefined limit can be substantially reduced. On the contrary, if the effect of uncertainty is strong, the time delay of migration entry (higher bold dotted line in figure) is stronger than the reduction of competition: in this case there is a reduction in migration inflow and an increase in the average time taken to reach the government's predefined stock.

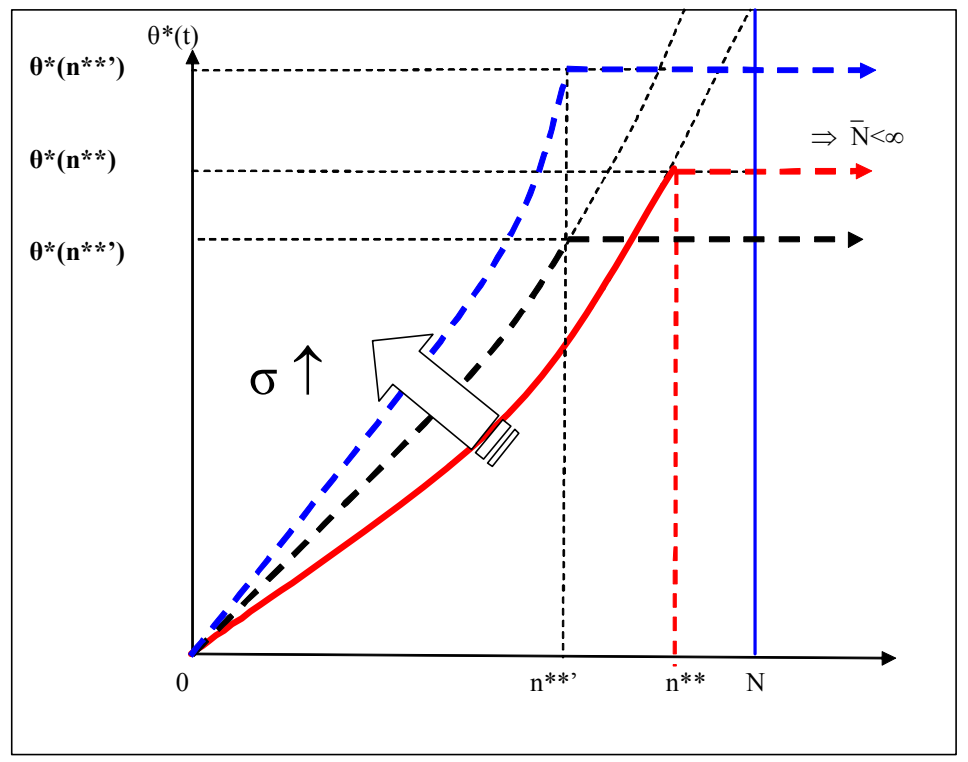

Figure 4. Undetermined limit over the stock: threshold levels for increasing variance

\section{Conclusion}

Recent European legislation on immigration reveals a peculiar paradox on migration policies. On the one hand, as a result of increased labour market competition and concerns about terrorism, the trend of recent legislation on immigration points to increasing frontier closure (OECD 1999, 2001). From the other, there is an increase in regularization: that is, European policies have become less tight. We have examined these conflicting policies by using a real option approach for migration choice which assumes that the decision to migrate can be described as an irreversible investment decision (Burda, 1995; Moretto and Vergalli, 2008). The model has focused on the government's desired immigrant stock and the policies adopted to control it. If a government adopts policies 
that go in the direction of tightening admission requirements by imposing quotas on the stock, it is as if it announces its stock target, which becomes perfectly predictable by potential immigrants. In this case our results agree with the economic literature (Bartolini, 1993) and show that potential immigrants may rush towards the host country because they are afraid of being excluded.

However, if a government is ambiguous about its migration programme, for example by adopting conflicting policies like alternating a tightening of admission requirements with regularization programs, this makes it difficult for a potential immigrant to predict the true stock target. In this case, we have shown that the government may be able to delay the mass entry of immigrants by improving its control over migration inflows (quotas). If this is the case then the counterbalancing immigration policies used by European countries are not paradoxical. They may be useful in indirectly delaying migration waves. Moreover, if certain governments have unstable majorities, that probably is expressed in counterbalancing migration policies, the migration inflow may become smooth regardless of the particular policy adopted, but also as a consequence of this political ambiguity. Furthermore, if a goverment's aim is to delay entry migration waves, it can control it by causing noise on information relating to the limit on immigration stock. In conclusion, there exists a third policy between the two policies adopted (tightening or reducing the rules for legal immigration): that is on alternation of tightening and reduction which may facilitate control over entry. 


\section{A Proof of proposition 1}

A family of solutions of (5) is given by:

$$
V(\theta, n, N)=A(n, N) \theta^{\gamma}+B(n, N) \theta^{\beta}+\hat{V}(\theta, n)
$$

where $\beta$ and $\gamma$ are the positive and negative roots of the quadratic equation in $\lambda:\left(\sigma^{2} / 2\right) \lambda(\lambda-1)+\alpha \lambda-\rho=0$ with $1<\beta<\frac{\rho}{\alpha}$ and $A(n, N)$ and $B(n, N)$ are the two families of integration constants; $\hat{V}(\theta, n)$ is chosen as the discounted expectation of flow payoff calculated by keeping the number of immigrants fixed at n:

$$
\hat{V}(\theta, n)=E_{0}\left[\int_{0}^{\infty} \pi(n, \theta) e^{-\rho t} d t \mid \theta_{0}=\theta\right]=\frac{\theta u(n)}{\rho-\alpha}
$$

Because the probability of entry tends to zero as $\theta$ tends to zero, one boundary condition is that $\lim _{\theta \rightarrow 0} V(\theta, n, N)=0$; this implies that $A(n, N)=0$, and then the equation:

$$
V(\theta, n, N)=B(n, N) \theta^{\beta}+\frac{\theta u(n)}{\rho-\alpha}
$$

in the text. The coefficient $B(n, N)$ can be determined by using the following suitable set of boundary conditions:

1. First, by competitive pressure, the value-matching condition requires the value of being entered is equal to the entry cost $K$ at $\theta=\theta^{*}(n)$, i.e., in equilibrium immigrants expect zero profit at entry (Dixit and Pindyck, 1994, ch.8).

$$
V\left(\theta^{*}(n), n, N\right)=K
$$

2. Second, as long as each individual rationally forecasts the future development of the whole market and new entries by competitors at the optimal entry threshold, we get (Bartolini, 1993; proposition 1; Grenadier, 2002, p. 699).:

$$
V_{n}\left(\theta^{*}(n), n, N\right)=0
$$

3. Third, on (6) for $n=N<\bar{N}$, yields (8) and $B(N, N)=0$.

Next, differentiating (21) totally with respect to $n$ and using (22) we get:

$$
\begin{aligned}
0 & =\frac{d V\left(\theta^{*}(n), n, N\right)}{d n}=V_{\theta}\left(\theta^{*}(n), n, N\right) \frac{\partial \theta(n)^{*}}{\partial n} \\
& =\left[\frac{u(n)}{\rho-\alpha}+B(n, N) \beta\left(\theta(n)^{*}\right)^{\beta-1}\right] \frac{\partial \theta(n)^{*}}{\partial n}
\end{aligned}
$$

This smooth pasting condition states that either each individual exercises his/her entry option at the level of $\theta$ at which the value is tangent to the entry cost, i.e., $V_{\theta}\left(\theta^{*}, n, N\right)=0$, or the optimal trigger $\theta^{*}(n)$ does not change with $n$. While the former means that the value function is smooth at entry and the trigger is a continuous function of $n$, the latter indicates that an individual would benefit from marginally anticipating or delaying his/her entry decision. In particular if $V_{\theta}\left(\theta^{*}, n, N\right)<0$ it means that the value of migrating is expected to increase if $\theta$ drops. On the contrary if $V_{\theta}\left(\theta^{*}, n, N\right)>0$ means that an individual would expect to make losses versus a future drop in $\theta$. In both situations (23) is satisfied by imposing $\frac{\partial \theta^{*}}{\partial n}=0$. 
Condition (23) splits $[0, N]$ into intervals where one of the following two conditions must hold:

$$
\left[\frac{u(n)}{\rho-\alpha}+B(n, N) \beta\left(\theta^{*}\right)^{\beta-1}\right]=0
$$

or

$$
\frac{\partial \theta^{*}(n)}{\partial n}=0
$$

Since $B(N, N)=0$ and $\frac{u(N)}{\rho-\alpha}>0$, then $(24)$ cannot hold at $n=N$. Therefore, it must be (25) that holds at $n=N$ and by (21):

$$
\theta^{*}(N)=(\rho-\alpha) \frac{K}{u(N)}
$$

Now, define $n^{*}$ as the largest $n \leq N$ that satisfies (24). For all $n^{*} \leq n \leq N$, we have $\frac{\partial \theta^{*}(n)}{\partial n}=0$, so that all immigrants in the range $\left[n^{*}, N\right]$ must enter at $\theta^{*}(N)$. In addition, since for the range $n<n^{*}(24)$ holds, applying this to the general solution $(20)$, gives as optimal range:

$$
\theta^{*}(n)=\frac{\beta}{\beta-1}(\rho-\alpha) \frac{K}{u(n)}
$$

Finally, the solution $n^{*}<N$ is obtained by combining (26) and (27), i.e.,

$$
\theta^{*}\left(n^{*}\right)=\theta^{*}(N) \Longrightarrow \frac{\beta}{\beta-1}(\rho-\alpha) \frac{K}{u\left(n^{*}\right)}=(\rho-\alpha) \frac{K}{u(N)}
$$

Let us now demonstrate the uniqueness of $n^{*}$. First, by $B(N, N)=0$, at $N, V(\theta, N, N)$ equals the discounted income stream with benefit fixed at $u(N)$ :

$$
V(\theta, N, N)=\hat{V}(\theta, N) \equiv \frac{\theta(t) u(N)}{\rho-\alpha}
$$

Then, to obtain $B(n, N)$, substitute (20) into (22): $B_{n}(n, N)=-\left(\theta^{*}\right)^{1-\beta} u^{\prime}(n) /(\rho-$ $\alpha$ ) and integrating between $n$ and $N$, gives:

$$
\int_{n}^{N} B_{q}(q, N) d q=-\int_{n}^{N}\left(\theta^{*}\right)^{1-\beta} \frac{u^{\prime}(q)}{\rho-\alpha} d q
$$

Using (1), $B(N, N)=0$, and changing the integration variable on the right-hand of $(29)$, gives

$$
B(n, N)=\frac{\pi^{* 1-\beta}}{\beta(\rho-\alpha)}\left[u^{\beta}(N)-u^{\beta}(n)\right]<0
$$

with $\lim _{n \rightarrow N} B(n, N)=0^{-}$. Substituting (30) into (23), we can define the condition (24) as the function:

$$
H(n)=\frac{u(n)}{\rho-\alpha}+\left(\frac{\pi^{*}}{\theta^{*}}\right)^{1-\beta} \frac{1}{(\rho-\alpha)}\left[u^{\beta}(N)-u^{\beta}(n)\right]
$$

with $H(N)>0$. If $H$ is still positive for a $N-y$ (where $y$ may be infinitesimally small), with $\frac{\pi^{*}}{\theta^{*}}=u(N)$ we ought to obtain $\frac{d \theta^{*}}{d n}=0$. This procedure continues until we obtain $y^{*}$ (defined by $n^{*}=N-y^{*}$ ) such that $H\left(n^{*}\right)=0$. Let us take the first derivative with respect to $y$ 


$$
\begin{aligned}
\frac{d H(N-y)}{d y} & =-\frac{u^{\prime}(N-y)}{\rho-\alpha}+\left(\frac{\pi^{*}}{\theta^{*}}\right)^{1-\beta} \frac{1}{(\rho-\alpha)} \beta u^{\beta-1}(N-y) u^{\prime}(N-y(\beta 2) \\
& =\frac{u^{\prime}(N-y)}{\rho-\alpha}\left[\left(\frac{\pi^{*}}{\theta^{*}}\right)^{1-\beta} \beta u^{\beta-1}(N-y)-1\right] \\
& =\frac{u^{\prime}(N-y)}{\rho-\alpha}\left[(u(N))^{1-\beta} \beta u^{\beta-1}(N-y)-1\right] \\
& =\frac{u^{\prime}(N-y)}{\rho-\alpha}\left[\beta\left(\frac{u(N-y)}{u(N)}\right)^{\beta-1}-1\right]<0
\end{aligned}
$$

Q.E.D. (Quod erat demonstrandum) if $y$ increases (moving from $N$ to 0 ) there exists a value of $n^{*}$ (i.e. $\left.y^{*}\right)$ such that $H\left(n^{*}\right)=0$.

\section{B Proof of Proposition 2.}

With uncertainty over stock $N$, equation (30) becomes:

$$
\begin{aligned}
E(B(n)) & =\frac{\pi^{* 1-\beta}}{\beta(\rho-\alpha)}\left[\int_{n}^{\bar{N}} u^{\beta}(N) g(N ; n) d N-u^{\beta}(n)\right] \\
& =\frac{\pi^{* 1-\beta}}{\beta(\rho-\alpha)}\left[\frac{\int_{n}^{\bar{N}} u^{\beta}(N) f(N) d N}{1-F(n)}-u^{\beta}(n)\right]<0
\end{aligned}
$$

which is negative because it is worth $u^{\beta}(n)>u^{\beta}(N)$ for any $N>n$. Furthermore, the limit of $E(B(n))$, yields:

$$
\begin{aligned}
\lim _{n \rightarrow \bar{N}} E(B(n)) & =\frac{\pi^{* 1-\beta}}{\beta(\rho-\alpha)}\left[\frac{\int_{n}^{\bar{N}} u^{\beta}(N) f(N) d N}{1-F(n)}-u^{\beta}(n)\right] \\
& =\frac{\pi^{* 1-\beta}}{\beta(\rho-\alpha)}\left[\frac{-u^{\beta}(n) f(n)}{-f(n)}-u^{\beta}(n)\right] \\
& =\frac{\pi^{* 1-\beta}}{\beta(\rho-\alpha)}\left[u^{\beta}(n)-u^{\beta}(n)\right]=0^{-}
\end{aligned}
$$

which is consistent with (11)..$^{28}$

The smooth pasting condition strongly depends on $E(B(n))$ :

$$
\begin{aligned}
E(H(n)) & =\frac{u(n)}{\rho-\alpha}+\beta \theta^{*^{\beta-1}} E(B(n)) \\
& =\frac{u(n)}{\rho-\alpha}+\left(\frac{\pi^{*}}{\theta^{*}}\right)^{1-\beta} \frac{1}{(\rho-\alpha)}\left[\frac{\int_{n}^{\bar{N}} u^{\beta}(N) f(N) d N}{1-F(n)}-u^{\beta}(n)\right]
\end{aligned}
$$

Since when $n \rightarrow \bar{N}$ we get $E(B(n))=0$, the smooth pasting reduces to $E(H(\bar{N}))=\frac{\underline{u}}{\rho-\alpha}>0$ which requires that $\frac{d \theta^{*}}{d n}=0^{29}$.

For the uniqueness of $n^{* *}$, assuming that $E(H(\bar{N}-y))>0$ so that $\frac{d \theta^{*}}{d n}=0$ and the optimal trigger is $\frac{\pi^{*}}{\theta^{*}}=\underline{u}$, we need to show that $d \frac{E(H(\bar{N}-y))}{d y}<0$. Substituting $\bar{N}-y$ into (34), we get:

$$
E(H(\bar{N}-y))=\frac{u(\bar{N}-y)}{\rho-\alpha}+(\underline{u})^{1-\beta} \frac{1}{(\rho-\alpha)}\left[\frac{\int_{\bar{N}-y}^{\bar{N}} u^{\beta}(x) f(x) d x}{1-F(\bar{N}-y)}-u^{\beta}(\bar{N}-y)\right]
$$


Taking the derivative:

$$
\begin{gathered}
d \frac{E(H(\bar{N}-y))}{d y}=-\frac{u^{\prime}(\bar{N}-y)}{\rho-\alpha}+(\underline{u})^{1-\beta} \frac{1}{(\rho-\alpha)} \times \\
\times\left[\frac{-u^{\beta}(\bar{N}-y) f(\bar{N}-y)\left(1-F(\bar{N}-y)-\int_{\bar{N}-y}^{\bar{N}} u^{\beta}(x) f(x) d x f(\bar{N}-y)\right.}{(1-F(\bar{N}-y))^{2}}\right. \\
\left.+\beta u^{\beta-1}(\bar{N}-y) u^{\prime}(\bar{N}-y)\right] \\
=\left[-\frac{u^{\beta}(\bar{N}-y) f(\bar{N}-y)}{(1-F(\bar{N}-y)}-\frac{\int_{\bar{N}-y}^{\bar{N}} u^{\beta}(x) f(x) d x f(\bar{N}-y)}{(1-F(\bar{N}-y))^{2}}+\beta u^{\beta-1}(\bar{N}-y) u^{\prime}(\bar{N}-y)\right] \\
+(\underline{u})^{1-\beta} \frac{1}{(\rho-\alpha)}\left[-\frac{u^{\beta}(\bar{N}-y) f(\bar{N}-y)}{(1-F(\bar{N}-y))}-\frac{\int_{\bar{N}-y}^{\bar{N}} u^{\beta}(x) f(x) d x f(\infty-y)}{(1-F(\bar{N}-y))^{2}}\right]= \\
d y-y)) \\
+(\underline{u})^{1-\beta} \frac{u^{\prime}(\bar{N}-y)}{\rho-\alpha-\alpha)}\left[-\frac{u^{\beta}(\bar{N}-y) f(\bar{N}-y)}{(1-F(\bar{N}-y))}-\frac{\int_{\bar{N}-y} u^{\beta}(x) f(x) d x f(\bar{N}-y)}{(1-F(\bar{N}-y))^{2}}\right]<0
\end{gathered}
$$

There thus exists a value $n^{* *}=\bar{N}-y^{* *}$ such that $E\left(H\left(n^{* *}\right)\right)=0$.

Finally we need to show that $n^{* *}<n^{*}$. To do so we need to show two conditions:

1. The value of $H(N-y)$ is greater than the value of $E[H(\bar{N}-y)]$ for any $y>y^{*}$.

2. The function (34) increases more rapidily than (31), i.e., the derivative (32) is greater than (35).

Condition 2 combined with condition 1 implies that the two functions do not intersect and that there exists a $y^{* *}$ such that $E\left[H\left(\bar{N}-y^{* *}\right)\right]=0$. For the first condition, stressing the analysis with respect to any point $y$ greater than $y^{*}$, we can show that (34) evaluated at $N-y$ (i.e. assuming $N$ as the upper limit of the stock) is lower than (31) if and only if:

$$
\frac{\int_{N-y}^{N} u^{\beta}(x) f(x) d x}{1-F(N-y)}<0
$$

which follows using the neoclassical properties. For the second condition, comparing (32) with (35) evaluated at $N-y$, we can show that:

$$
\frac{d H(N-y)}{d y}>d \frac{E(H(N-y))}{d y}
$$

This result can be shown in the following figure 5: 


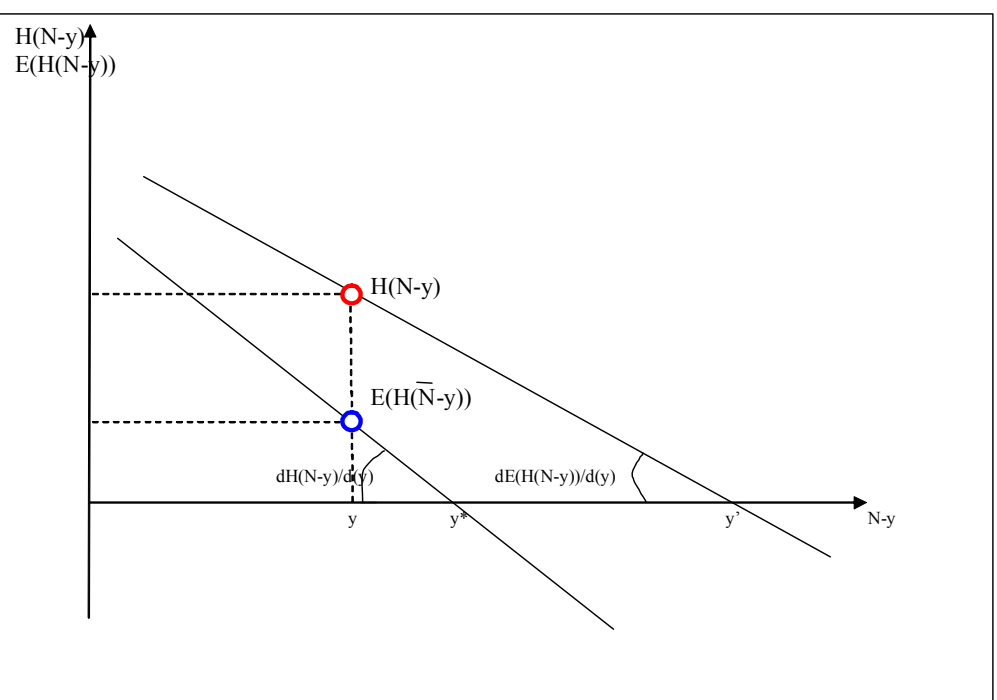

Figure 5: Graphic Solution 


\section{Notes}

${ }^{1}$ We must stress a first caveat concerning the definition of "quota". In SOPEMI International Migration Outlook (2006) "quota" is defined as the share of total immigrants that is assigned to a particular group. Therefore, for any given group, it quantifies the percentage of the total stock admitted in a lapse of time.

2 "Schäuble-Sarkozy suggested that EU asylum policy should be centralised, that long-term economic immigration should be managed by quotas and that short-term immigration should be regulated by temporary visas", Editorial of Intereconomics, (2006).

${ }^{3}$ In their broadest sense, regularization programs offer those migrants who are in a country without authorization the opportunity to legalize their status. Irregular migrants, also referred to as "undocumented," "unauthorized," or "illegal," are defined by most states as those migrants who have either entered a country legally and then fallen out of legal status such as students, temporary workers, rejected asylum seekers, or tourists - or those who have entered illegally, either by crossing a border undetected or with false documents. In either case, irregular migrants do not have a legal right to residence in the state to which they have migrated.

${ }^{4}$ Bartolini (1993, 1995), develops a general model that considers the investment decision of decentralized profit-maximizing agents who face investment adjustment costs in a market with stochastic returns and a limit on aggregate investment. The model is consistent with equilibrium models of asset pricing under uncertainty but differs from the mainstream assumption of constant investment cost by assuming that, for technological or institutional reasons, the investment cost is constant only until an investment ceiling becomes binding. At that point, in fact, Bartolini shows that cost becomes infinite. His paper shows that a competitive market reacts to this type of externality by generating recurrent runs as aggregate investment approaches its limit.

${ }^{5}$ The existence of limits seems to be idiosyncratic with respect to various aspects of the economic approach. Particularly, it can be used not only to study migration phenomenon, by also concerning foreign investment or also the adoption of licenses regulating the market. We can find many examples in which bounds assume an important role in the market. Capital controls are often imposed to prevent a country's net credit position from exceeding some acceptable levels; central banks face limits on the amount of foreign reserves that can be used to enforce an exchange rate target; firms in a fast-growing industry or in a developing economy may be competing for extended periods for a small number of qualified managers or highly skilled workers; entry of firms is restricted in many industries by regulations aimed at containing market size or by technological constraints on the use of a scarce resource. Similar approaches arise for taxi and liquor licences, fishing and costal trade rights, the number of polluting trade permits or ecolabelling permits (Dosi and Moretto, 2001).

${ }^{6}$ Indeed, as stressed in the OECD International Migration Outlook (2006), "In practice, however, the national limits and associated quotas have been less than the numbers requested by employers and have proven to be significantly under actual labour market needs, if the extent of regularisations of persons with employment contracts is any indication [...] the regular lack of concordance between the programmed migration levels and labour market needs meant that in practice, the levels had become almost irrelevant. Employers may well have become accustomed to a situation in which they could hire outside legal channels with relative impunity, with a reasonable probability that the hiring would be formally recognised a few years hence through regularisation".

${ }^{7}$ The indexes from 1 to 6 were defined by Fondazione Rodolfo Debenedetti (see www.frdb.org for details) and the index 7 was defined by Hatton (2004).

8"All countries except Greece, [...] denote a tightening in regulations", see Boeri and Brücker, 2005, page 634 .

${ }^{9}$ We have compiled Table 1 by drawing on European immigration databases and sources. Table 1 concerns Europe in the geographical sense.

${ }^{10}$ Table 2 is our elaboration on Jachimowicz et al. (2004, pages 36-40) and Sunderhaus, (2007).

${ }^{11}$ See Dixit-Pindyck (1994, pag. 253); Bartolini (1993); Moretto (2008) and Moretto and Vergalli (2008). 
${ }^{12}$ This means that we take the differential wages into account. Hence equation (1) is in line with this definition, as also shown by other recent papers (Vergalli; 2008; Moretto and Vergalli, 2008).

${ }^{13}$ As stressed by Epstein and Nitzan (2006), "empirical evidence from the EU countries shows that immigration had at most a very small impact on wages and employment opportunities of natives". Moreover, "most of the evidence on the effect of immigrants on wages (and employment) for the US is also ambiguous in the sense that some studies show small positive effects and others small negative effects". In line with this empirical evidence we study the migration process without taking account of the crossed effect on natives' wages and unemployment level.

${ }^{14}$ On this see Bauer, Epstein and Gang, (2002), Epstein and Gang (2004), Moretto and Vergalli (2008), and Vergalli (2007).

${ }^{15}$ In other words, the reserve value $\underline{u}$ measures the level of "desperation" of the potential immigrants.

${ }^{16}$ For details on the process, see Dixit and Pindyck (1994, pag. 71).

${ }^{17}$ In this case we assume that the shock is homogeneous for all immigrants. If the shock were individual-specific, the model should change by considering the immigrants as they had different skills (i.e., they could perceive different wage gaps). The result would be a change of scale in the trigger levels and a self-selection of immigrants, but the theoretical result would not change. For more details, see Vergalli (2007), page 12. Therefore, we use a homogeneous shock as a general model.

${ }^{18}$ That is, the sum of the instantaneous dividend (benefit) flow and the expected capital gain equals normal profits (Dixit and Pindyck, 1994, p. 185).

${ }^{19}$ Where $V_{\theta}=\frac{\partial V}{\partial \theta}$ and $V_{\theta \theta}=\frac{\partial^{2} V}{\partial \theta^{2}}$.

${ }^{20}$ That is, the discounted present value of the benefit flows over an infinite horizon starting from $\theta$ (Harrison 1985, p. 44). See equation (19) in the Appendix.

${ }^{21}$ This condition is familiar in the real option theory with the name of matching value condition (see Dixit and Pindyck, 1994).

${ }^{22}$ See condition (23) in the Appendix.

${ }^{23}$ It is worth noting that the "utility" threshold that triggers migration for individual immigrants is identical to that of the individual that correctly anticipates the other immigrants' strategies. This property, discovered first by Leahy (1993), has an important operative implication; i.e., the optimal migration policy of each individual need not take account of the effect of rivals' entry. He/she can behave competitively as if he/she is the last to enter. In other words, when an individual decides to enter, by pretending to be the last to migrate, he/she is ignoring two things: 1) He/she is thinking that his/her benefit flow is given by $u(n) \theta$, with $n$ held fixed forever. Thus, as $u^{\prime}(n)<0$, he/she is ignoring that future entry by other members, in response to a higher value of $\theta$, will reduce "utility". All things being equal, this would make entry more attractive for the migrant that behaves myopically. 2) $\mathrm{He} / \mathrm{she}$ is unaware that the prospect of future entry by competitors reduces the option value of waiting. That is, pretending to be the last to migrate, the individual also believes he/she still has a valuable option of waiting before making an irreversible decision. All things being equal, this makes the decision to enter less attractive. The two effects offset each other, allowing the migrant to act as if in isolation (see Dixit and Pindyck, 1994, p. 291).

${ }^{24}$ Obviously, a government sets the stock in line with the supply-demand gap of the labour market. Indeed, "the selection of candidates for immigration can be made by the receiving country itself [...] In this case, potential immigrants are screened on the basis of certain characteristic, deemed to contribute to, and facilitate, integration in the host country, such as $[\ldots]$ having an occupation deemed to be in shortage and having a prior job offer from an employer in the host country" (Sopemi, 2006, page 114).

The ambiguity concerning the quota can exist when the government adopts confused immigration policies. This may be due to many causes: for example, when different political parties alternate in the government of a country, probably expressing different and contradictory policies; or when the authority imposes an exacerbation of admission requirements and regularization programs at the same time. 
${ }^{25}$ The upper support of the distribution can be set to $\hat{N} \leq \bar{N}$. Without losing generality we assume that $\hat{N}=\bar{N}$.

${ }^{26}$ This is due to the fact that $\frac{d \frac{\beta}{\beta-1}}{d \sigma}>0$ and $\frac{d u(n)}{d n}<0$.

${ }^{27}$ We concentrate the analysis on the case of an unknown quota. Obviously, we have the same effect with a known quota.

${ }^{28}$ Note that $\lim _{n \rightarrow \infty} E(B(n))=0$ even if $u(n) \rightarrow \underline{\mathrm{u}} \geq 0$.

${ }^{29}$ Note that this result always holds for $\underline{u}>0$, but it is also true for $\underline{u} \geq 0$ by using limit definition. In this case for each real number $\varepsilon>0$ infinitesimely small, there exists a value $n$ ' such that for $n>n$ I the difference

$$
E\left(H\left(n^{\prime}\right)\right)-E(H(\infty))<\varepsilon
$$

Nevertheless, because now $E(H(\infty))=0$, we are able to find a value $n^{\prime}$ such that:

$$
E\left(H\left(n^{\prime}\right)\right)-0<\varepsilon
$$

If $\varepsilon \rightarrow 0$ it follows that $n^{\prime}$ is the right value we are searching. 


\section{References}

[1] Anam, M., S., H., Chiang and L., Hua, (2007), "Uncertainty and International Migration: an Option cum Portfolio Model", Journal of Labor Research, Springer New York, online publication

[2] Bartolini, L., (1993), "Competitive runs", European Economic Review, n. $37,921-948$

[3] Bartolini, L., (1995), "Foreign Investment Quotas and Rent Extraction Under Uncertainty", Journal of International Economics, n. 38, 25-49

[4] Bauer, T., G., Epstein and I., N., Gang, (2002), "Herd Effects or Migration Networks? The Location Choice of Mexican Immigrants in the U.S.", IZA Discussion Paper, N. 551

[5] Boeri, T., and H., Brücker, (2005), "Why are Europeans so tough on migrants?", Economic Policy, 20(44), 630-703

[6] Burda, M., C., (1995), "Migration and the Option Value of Waiting", The Economic and Social Review, 27, pp. 1-19

[7] Dixit, A., K., (1995), "Irreversible Investment with Uncertainty and Scale Economies", Journal of Economic Dynamics and Control, 19(1), 327-350

[8] Dixit, A., and R., S., Pindyck, (1998), "Expandibility, Reversibility, and Optimal Capacity Choice", NBER Working Paper No. W6373

[9] Dixit, A., and R., S., Pindyck, (1994), "Investment under Uncertainty", Princeton (NJ): Princeton University Press

[10] Dosi, C., and M., Moretto, (2001), "Is Ecolabbeling a Reliable Environmental Policy Measure?", Environmental and Resource Economics, 19, 113-127

[11] Epstein, G., S., and S., Nitzan, (2006), "The struggle over migration policy", Journal of Population Economics, 19/4, 703-723

[12] Epstein, G., S., and I., Gang, (2004), "Ethnic Networks and International Trade", CEPR Discussion Paper, 4616

[13] European Migration Network, (2007), "Conditions of Entry and Residence of Third Country Highly-Skilled Workers in EU", http://www.europeanmigration-network.org

[14] Faini, R., J., DeMelo and K., F., Zimmermann, (1999), "Migration: The Controversies and the Evidence", Cambridge University Press, Cambridge

[15] Feist, H., (1998), "Wage-distance Regulation in Social-welfare Programs: an Option-theory Perspective", Journal of Economics, 68, pp. 271-293

[16] Fondazione Rodolfo De Benedetti, http://www.frdb.org/

[17] Grenadier, S., R., (2002), "Option Exercise Games: An Application to the Equilibrium Investment Strategies of Firms", Review of Financial Studies, $15,691-721$

[18] Harrison, J., M., (1985), "Brownian Motion and Stochastic Flow Systems", New York: John Wiley \& Son

[19] Hatton, T., J., (2004), 'Seeking asylum in Europe', Economic Policy, April, 5-62 
[20] Hill, K., J., (1987), "Immigrant Decisions Concerning Duration of Stay and Migratory Frequency", Journal of Development Economics 25, 221-234

[21] Intereconomics, Editorial of, (2006), "Towards a European Migration Policy", Vol. 41, Vol. 6

[22] Khwaja, Y., (2002), "Should I Stay or Should I Go? Migration Under Uncertainty: A Real Option Approach", Public Policy Discussion Papers 02-10, Economics and Finance Section, School of Social Sciences, Brunel University

[23] Jachimowicz, M., G., Demetrios and K., O., Papademetriou, (2004), "Observations on Regularization and the Labor Market Performance of Unauthorized and Regularized Immigrants", Migration Policy Institute, Paper Prepared for the European Commission, DG Employment and Social Affairs

[24] Leahy, J., P., (1993), "Investment in Competitive Equilibrium: the Optimality of Myopic Behavior", Quarterly Journal of Economics, 108, pp. $1105-1133$

[25] Levinson, A., (2005), "Why Countries Continue to Consider Regularization", Migration Information Source

[26] Mavitra, le marché virtuel du travail dans le Bassin Méditerranéen, www.mavitra.org

[27] Migration Information Source, http://www.migrationinformation.org

[28] Moretto, M., (2008), "Competition and Irreversible Investment under Uncertainty", Information Economics and Policy, 20, pp. 75 - 88

[29] Moretto, M., and S., Vergalli, (2008), "Migration Dynamics", Journal of Economics, 93, Vol. 3, pp. 223 - 265

[30] Dixit, A., K., (1995), "Irreversible Investment with Uncertainty and Scale Economies", Journal of Economic Dynamics and Control, 19(1), 327-350

[31] OECD, (1999), Trends in International Migration, SOPEMI, Paris

[32] OECD, (2001), Trends in International Migration, SOPEMI, Paris

[33] OECD, (2004), Trends in International Migration, SOPEMI, Paris

[34] SOPEMI, (2006), International Migration Outlook

[35] Sjaastad, L., A., (1962), "The Costs and Returns of Human Migration", The Journal of Political Economy, 70(5), Part 2, pp. 80-93

[36] Sunderhaus, S., (2007), "Regularization Programs for Undocumented Migrants", Migration Letters, 4(1), pp. 65-76

[37] Vergalli, S., (2008), "The Role of Community in Migration Dynamics", Labour, Review of Labour Economics and Industrial Relations (forthcoming)

[38] Vergalli, S., (2007), "Entry and Exit Strategies in Migration Dynamics", University of Brescia Discussion Paper n. 0701

[39] Work Permit, http: workpermit.com 


\section{CESifo Working Paper Series}

for full list see www.cesifo-group.org/wp

(address: Poschingerstr. 5, 81679 Munich, Germany, office@cesifo.de)

2669 Aleksandra Riedl and Silvia Rocha-Akis, Testing the Tax Competition Theory: How Elastic are National Tax Bases in OECD Countries?, June 2009

2670 Dominique Demougin and Carsten Helm, Incentive Contracts and Efficient Unemployment Benefits, June 2009

2671 Guglielmo Maria Caporale and Luis A. Gil-Alana, Long Memory in US Real Output per Capita, June 2009

2672 Jim Malley and Ulrich Woitek, Productivity Shocks and Aggregate Cycles in an Estimated Endogenous Growth Model, June 2009

2673 Vivek Ghosal, Business Strategy and Firm Reorganization under Changing Market Conditions, June 2009

2674 Francesco Menoncin and Paolo M. Panteghini, Retrospective Capital Gains Taxation in the Real World, June 2009

2675 Thomas Hemmelgarn and Gaëtan Nicodème, Tax Co-ordination in Europe: Assessing the First Years of the EU-Savings Taxation Directive, June 2009

2676 Oliver Himmler, The Effects of School Competition on Academic Achievement and Grading Standards, June 2009

2677 Rolf Golombek and Michael Hoel, International Cooperation on Climate-Friendly Technologies, June 2009

2678 Martin Cave and Matthew Corkery, Regulation and Barriers to Trade in Telecommunications Services in the European Union, June 2009

2679 Costas Arkolakis, A Unified Theory of Firm Selection and Growth, June 2009

2680 Michelle R. Garfinkel, Stergios Skaperdas and Constantinos Syropoulos, International Trade and Transnational Insecurity: How Comparative Advantage and Power are Jointly Determined, June 2009

2681 Marcelo Resende, Capital Structure and Regulation in U.S. Local Telephony: An Exploratory Econometric Study; June 2009

2682 Marc Gronwald and Janina Ketterer, Evaluating Emission Trading as a Policy Tool Evidence from Conditional Jump Models, June 2009

2683 Stephan O. Hornig, Horst Rottmann and Rüdiger Wapler, Information Asymmetry, Education Signals and the Case of Ethnic and Native Germans, June 2009 
2684 Benoit Dostie and Rajshri Jayaraman, The Effect of Adversity on Process Innovations and Managerial Incentives, June 2009

2685 Peter Egger, Christian Keuschnigg and Hannes Winner, Incorporation and Taxation: Theory and Firm-level Evidence, June 2009

2686 Chrysovalantou Milliou and Emmanuel Petrakis, Timing of Technology Adoption and Product Market Competition, June 2009

2687 Hans Degryse, Frank de Jong and Jérémie Lefebvre, An Empirical Analysis of Legal Insider Trading in the Netherlands, June 2009

2688 Subhasish M. Chowdhury, Dan Kovenock and Roman M. Sheremeta, An Experimental Investigation of Colonel Blotto Games, June 2009

2689 Alexander Chudik, M. Hashem Pesaran and Elisa Tosetti, Weak and Strong Cross Section Dependence and Estimation of Large Panels, June 2009

2690 Mohamed El Hedi Arouri and Christophe Rault, On the Influence of Oil Prices on Stock Markets: Evidence from Panel Analysis in GCC Countries, June 2009

2691 Lars P. Feld and Christoph A. Schaltegger, Political Stability and Fiscal Policy - Time Series Evidence for the Swiss Federal Level since 1849, June 2009

2692 Michael Funke and Marc Gronwald, A Convex Hull Approach to Counterfactual Analysis of Trade Openness and Growth, June 2009

2693 Patricia Funk and Christina Gathmann, Does Direct Democracy Reduce the Size of Government? New Evidence from Historical Data, 1890-2000, June 2009

2694 Kirsten Wandschneider and Nikolaus Wolf, Shooting on a Moving Target: Explaining European Bank Rates during the Interwar Period, June 2009

2695 J. Atsu Amegashie, Third-Party Intervention in Conflicts and the Indirect Samaritan's Dilemma, June 2009

2696 Enrico Spolaore and Romain Wacziarg, War and Relatedness, June 2009

2697 Steven Brakman, Charles van Marrewijk and Arjen van Witteloostuijn, Market Liberalization in the European Natural Gas Market - the Importance of Capacity Constraints and Efficiency Differences, July 2009

2698 Huifang Tian, John Whalley and Yuezhou Cai, Trade Sanctions, Financial Transfers and BRIC's Participation in Global Climate Change Negotiations, July 2009

2699 Axel Dreher and Justina A. V. Fischer, Government Decentralization as a Disincentive for Transnational Terror? An Empirical Analysis, July 2009

2700 Balázs Égert, Tomasz Koźluk and Douglas Sutherland, Infrastructure and Growth: Empirical Evidence, July 2009 
2701 Felix Bierbrauer, Optimal Income Taxation and Public Goods Provision in a Large Economy with Aggregate Uncertainty, July 2009

2702 Marc Gronwald, Investigating the U.S. Oil-Macroeconomy Nexus using Rolling Impulse Responses, July 2009

2703 Ali Bayar and Bram Smeets, Government Deficits in the European Union: An Analysis of Entry and Exit Dynamics, July 2009

2704 Stergios Skaperdas, The Costs of Organized Violence: A Review of the Evidence, July 2009

2705 António Afonso and Christophe Rault, Spend-and-tax: A Panel Data Investigation for the EU, July 2009

2706 Bruno S. Frey, Punishment - and beyond, July 2009

2707 Michael Melvin and Mark P. Taylor, The Crisis in the Foreign Exchange Market, July 2009

2708 Firouz Gahvari, Friedman Rule in a Model with Endogenous Growth and Cash-inadvance Constraint, July 2009

2709 Jon H. Fiva and Gisle James Natvik, Do Re-election Probabilities Influence Public Investment?, July 2009

2710 Jarko Fidrmuc and Iikka Korhonen, The Impact of the Global Financial Crisis on Business Cycles in Asian Emerging Economies, July 2009

2711 J. Atsu Amegashie, Incomplete Property Rights and Overinvestment, July 2009

2712 Frank R. Lichtenberg, Response to Baker and Fugh-Berman's Critique of my Paper, "Why has Longevity Increased more in some States than in others?", July 2009

2713 Hans Jarle Kind, Tore Nilssen and Lars Sørgard, Business Models for Media Firms: Does Competition Matter for how they Raise Revenue?, July 2009

2714 Beatrix Brügger, Rafael Lalive and Josef Zweimüller, Does Culture Affect Unemployment? Evidence from the Röstigraben, July 2009

2715 Oliver Falck, Michael Fritsch and Stephan Heblich, Bohemians, Human Capital, and Regional Economic Growth, July 2009

2716 Wladimir Raymond, Pierre Mohnen, Franz Palm and Sybrand Schim van der Loeff, Innovative Sales, R\&D and Total Innovation Expenditures: Panel Evidence on their Dynamics, July 2009

2717 Ben J. Heijdra and Jochen O. Mierau, Annuity Market Imperfection, Retirement and Economic Growth, July 2009 
2718 Kai Carstensen, Oliver Hülsewig and Timo Wollmershäuser, Price Dispersion in the Euro Area: The Case of a Symmetric Oil Price Shock, July 2009

2719 Katri Kosonen and Gaëtan Nicodème, The Role of Fiscal Instruments in Environmental Policy, July 2009

2720 Guglielmo Maria Caporale, Luca Onorante and Paolo Paesani, Inflation and Inflation Uncertainty in the Euro Area, July 2009

2721 Thushyanthan Baskaran and Lars P. Feld, Fiscal Decentralization and Economic Growth in OECD Countries: Is there a Relationship?, July 2009

2722 Nadia Fiorino and Roberto Ricciuti, Interest Groups and Government Spending in Italy, 1876-1913, July 2009

2723 Andreas Wagener, Tax Competition, Relative Performance and Policy Imitation, July 2009

2724 Hans Fehr and Fabian Kindermann, Pension Funding and Individual Accounts in Economies with Life-cyclers and Myopes, July 2009

2725 Ernesto Reuben and Arno Riedl, Enforcement of Contribution Norms in Public Good Games with Heterogeneous Populations, July 2009

2726 Kurt Schmidheiny and Marius Brülhart, On the Equivalence of Location Choice Models: Conditional Logit, Nested Logit and Poisson, July 2009

2727 Bruno S. Frey, A Multiplicity of Approaches to Institutional Analysis. Applications to the Government and the Arts, July 2009

2728 Giovanni Villani, A Strategic R\&D Investment with Flexible Development Time in Real Option Game Analysis, July 2009

2729 Luca Di Corato and Michele Moretto, Investing in Biogas: Timing, Technological Choice and the Value of Flexibility from Inputs Mix, July 2009

2730 Gilad D. Aharonovitz, Nathan Skuza and Faysal Fahs, Can Integrity Replace Institutions? Theory and Evidence, July 2009

2731 Michele Moretto and Sergio Vergalli, Managing Migration through Conflicting Policies: an Option-theory Perspective, July 2009 